\title{
Quais conceitos permeiam o discurso do presidente da Telemar S/A sobre a mudança da empresa com a privatização? Uma análise através de Mapas Cognitivos

\author{
Luciana de Oliveira Faria
}

\section{Resumo:}

Este trabalho propõe, utilizando a ferramenta dos mapas cognitivos, analisar o discurso do presidente da Telemar S/A ${ }^{1}$, Manoel Horácio Francisco da Silva, proferido em três entrevistas que concedeu entre 1999 e 2000 sobre o processo de transformação organizacional devido a privatização da empresa. O objetivo do trabalho é identificar os principais conceitos utilizados pelo presidente para, assim, tentar levantar os princípios com os quais conduz e facilita a mudança. $O$ presente trabalho está dividido em seis partes: a primeira é a própria introdução e apresenta o tema da Cognição Social, introduzindo o conceito de mapas cognitivos. A segunda parte aprofunda mais esse último conceito e descreve suas tipologias, ressaltando que os mapas cognitivos serão utilizados no presente trabalho como instrumento facilitador da compreensão dos conceitos que guiam o presidente da empresa em suas ações. A terceira parte introduz o tema da mudança organizacional e de como ela vem sendo tratada nos estudos atuais de organização. A quarta, faz uma breve passagem pelo contexto atual do Setor de Telecomunicações. Na quinta parte, é apresentado o desenho do mapa cognitivo proposto e uma interpretação para ele. Finalmente, na sexta e última parte são apresentadas as considerações finais do trabalho.

\begin{abstract}
$>$

$>$ This work proposes to analyse the speech of the CEO of Telemar, Manoel

$>$ Horacio Francisco da Silva, in three interviews held in 1999 and 2000 about

$>$ the organizational chance processes due to the company privatization. It

>uses the cognitive maps method. The present paper is divided into six parts:

$>$ the first one, presents the Social Cognition, introducing the concept of

$>$ Cognitive Maps. The second part reinforces this last concept and describes

$>$ its typologies, pointing out that the Cognitive Maps were used as a tool to

$>$ make easy the understanding of the concepts that guide the CEO throught his

$>$ actions. The third part introduces the organizational change process and how

$>$ it has been seen in the present Organizational Studies. The fourth, traces

$>$ the contemporary reality of the telecommunications Industry. In the fifth

>part, a drawing of the cognitive map proposed is presented as well as an

$>$ interpretation of it. Finally, in the sixth and last part, the work final

$>$ considerations are presented.
\end{abstract}

\footnotetext{
${ }^{1}$ Com a privatização do setor de Telecomunicações, a Telemar S/A -Tele Norte Leste Participações S/A- obteve a concessão para atuar na prestação de serviços de telefonia fixa na Região I do Plano Geral de Outorgas e engloba os Estados de RJ, MG, ES, BA SE, AL, PE, PB, RN, CE, PI, MA, PA, AP, AM e RO. Anteriormente o setor constituía monopólio estatal e as empresas de telecomunicações dos Estados eram holdings do Sistema Telebrás estatal.
} 


\section{A Cognição Social}

Na última década, conforme Tenbrunsel et al. (1996), o estudo do comportamento organizacional testemunhou uma mudança dramática em direção a uma perspectiva mais cognitiva. A corrente de estudos chamada Cognição Social teve suas origens na Psicologia Cognitiva. A Cognição Social em organizações, como ressalta Jr (1992), é o estudo do processamento de informação humana (consciente e inconsciente) na medida que influencia e é influenciada pelo fenômeno complexo social e estrutural dentro das organizações modernas. A visão cognitiva encara a organização de uma forma bastante diferente dos estudos anteriores em organizações: ela procura entender o mundo como ele é e não como gostaríamos que ele fosse ou como deveria ser. Sua origem data dos trabalhos de Chester Barnard, que enfatizava que as ações dentro das organizações são condicionadas pela maneira com a qual seus membros percebem o mundo, assim que o ambiente de uma organização é percebido subjetivamente. A cognição analisa as organizações sob o ponto de vista mais humano, mais difuso e complexo, admitindo a possibilidade da existência constante de divergências.

Segundo Nicolini (1999), o esforço de entender e descrever o fenômeno organizacional em termos cognitivos levou à criação - ou o empréstimo de outras ciências- de vários métodos e técnicas com as quais investiga-se os processos cognitivos de membros e organizações. Alguns acadêmicos ${ }^{i}$ acreditam que o uso de uma metodologia apropriada torna possível capturar e representar os construtos mentais que efetivamente guiam os atores em seu comportamento diário. Esses acadêmicos afirmam que indivíduos e organizações processam informação do ambiente usando algum tipo de estrutura de conhecimento, isto é, "um modelo mental que indivíduos impõem a uma informação para dar-lhe forma e significado"(Walsh 1995:281).

Nicolini (1999) ainda afirma que representações simbólicas e estruturas mentais têm um papel central na abordagem cognitiva: juntas, encapsulam um fenômeno complexo; um processo que, de um lado, retira e de outro, reconstrói e organiza características préestabelecidas com elementos independentes num ambiente externo. Ao mesmo tempo, representações simbólicas e estruturas mentais possuem um papel mediador entre estímulo e resposta, daí que o objetivo da abordagem é atribuir propriedades causais aos desejos das pessoas, convicções e vontades, quer dizer, estabelecer se são representativos ou acima de tudo intencionais, fisicamente possíveis e capazes de gerar comportamentos. Assim, é legítimo e necessário colocar um nível de análise separado e de entidades que deve ser chamado de nível de "representação", porque esse nível é necessário para explicar a variedade do comportamento humano, pensamento e ação (Gardner, 1985). Quando um cientista trabalha com este nível, ele está lidando com entidades representativas como estruturas do conhecimento, símbolos, regras e imagens - a questão da representação que está entre o input e o output.

Outros autores desconfiam da possibilidade de mapear as estruturas cognitivas e da eficácia das técnicas propostas, já que a correlação entre a "verdade" e os mapas causais nunca é perfeita e é modelada pela natureza do discurso público e do contexto onde acontece. Nicolini (1999) afirma que os mapas cognitivos são representações de representações, e, portanto, não podem pretender capturar 'o que está na mente do ator organizacional'; processos de pensamento e estrutura de discurso interagem e interferem entre si, 
especialmente na presença de metodologia particular representativa e de um pesquisador que dá configuração específica para o contexto no qual o mapa cognitivo é construído.

De acordo com Nicolini (1999), os mapas devem, portanto, ser considerados somente como instrumentos de representação que ajudam a discussão e a análise de certos modos de pensamentos e explicação de eventos. Os mapas são extremamente úteis, porque as oportunidades que podem produzir e interagir, uma descrição das maneiras nas quais certas classes de fenômenos são interpretados, se tornam a base para uma experiência de autoreflexão que produz aprendizado e mudança. Os métodos para mapear cognição organizacional, como para qualquer outro sistema representacional e estratégia, não se limitam a codificar a realidade "de fora" em termos de fatos, objetos e eventos, mas constróem esses elementos clareando certos aspectos e conciliando ou contrastando outros.

A Cognição Social tenta identificar como as pessoas pensam sobre pessoas, situações e pessoas em determinados contextos. É nesse sentido que se propõe este trabalho. Parte-se da crença de que os mapas cognitivos são ferramentas úteis para uma melhor compreensão dos fenômenos organizacionais e, por isso, utiliza-os na análise de três discursos do presidente da Telemar S/A, Manoel Horácio Francisco da Silva, sobre a mudança organizacional da empresa, que sofreu um processo de privatização. Essa análise é realizada no intuito de identificar o que o presidente pensa - seus construtos mentais- sobre a mudança organizacional sofrida com o processo de Privatização da empresa iniciado em 1998.

\section{Os Mapas Cognitivos}

De acordo com Bastos (2000), o conceito de mapa cognitivo surge na Psicologia à partir dos experimentos de E. Tolman, estudando, em ratos, a aprendizagem e a orientação em labirintos. Mapas eram representações de indícios visuais, táteis, auditivos, que configuram o ambiente e permitem a localização do sujeito no espaço. Segundo Csányi (1995), a quase totalidade dos animais utilizam mapas cognitivos para se orientarem e estes mesmos mapas são representações dinâmicas do ambiente. No homem, no entanto, segundo este mesmo autor, há uma mudança substantiva. Com a sua competência lingüística, modifica-se o meio pelo qual o ambiente é mapeado. Este deixa de ser perceptual e passa a ser um mapeamento lingüístico, de conceitos. Os mapas cognitivos humanos são realidades socialmente construídas.

Segundo Pidd (1998), termos e definições são importantes na cognição social. Pessoas tendem a agrupar objetos, indivíduos, papéis sociais e eventos comuns em grupos equivalentes em seus processos de pensamento. Esses grupos são chamados de categorias e, diretamente relacionada com as categorias é a idéia de esquema, que representa a organização do pensamento sobre um conceito particular. $\mathrm{O}$ esquema contém as características ou atributos que estão associados com os membros das categorias. Os esquemas (mentais) são construídos através de experiências com instâncias específicas. As pessoas entendem o mundo construindo modelos em sua mente que são incompletos e mais simples que as entidades que eles representam. As pessoas não partilham mapas idênticos. O mapa cognitivo é uma maneira de capturar as visões das pessoas, de forma a desenvolver um modelo explícito destas visões, capturando o mapa do seu pensamento, tentando entender o conceito que usam e como estes conceitos estão interligados. 
De acordo com Swan (1997), os mapas cognitivos são representações, schemas ou modelos mentais construídos pelos indivíduos, a partir das suas interações e aprendizagens em um domínio específico do seu ambiente, e que cumprem a função de dar sentido à realidade e permitir lidar com os problemas e desafios que esta lhes coloca. Mapeando o esquema e a estrutura conceitual de uma pessoa, nós mapeamos sua representação do ambiente, que é uma abstração intensa de sua experiência (Weick, 1977).

Segundo Pidd (1998), a motivação para o mapeamento cognitivo é a percepção de que, embora as pessoas possam ter diferentes entendimentos da mesma situação, estes diferentes entendimentos podem, freqüentemente, ser racionalmente compreendidos. De acordo com Éden et al. (1989), as diferentes abordagens de mapeamento são baseadas em um conjunto de pressupostos que derivam da teoria dos construtos pessoais ${ }^{\text {ii }}$, esta é uma estrutura básica na psicologia cognitiva.

A idéia do mapeamento cognitivo é desenvolver um esquema gráfico dos construtos interligados que as pessoas parecem empregar, quando raciocinam a respeito do que acontece em relação à situação problemática (Pidd, 1998).

É bom ressaltar, conforme Bastos (2000), que estes mapas não devem ser vistos como representações estáticas; eles são sempre atualizados a partir das experiências de aprendizagem do sujeito. Isto é, os modelos que construímos do mundo estão continuamente sendo desafiados a incorporar novas informações de forma que eles cumpram a função básica de permitir o 'ajustamento' do sujeito ao seu meio ambiente. Os mapas cognitivos envolvem formas de analisar os dados e retratar graficamente as crenças subjetivas acessadas, dandolhes um tratamento espacial que facilite a visualização das relações significativas identificadas. Eles não são cópias exatas do ambiente. Segundo Lazlo et al.

“...um mapeamento, portanto, perece-se com uma tradução de uma linguagem para outra. A tradução nunca é perfeita. Algo do sabor e da substância do original é sempre perdido em uma tradução". (1995:2)

De acordo com Bastos (2000), os mapas podem ser construídos a partir de dados brutos de diferentes naturezas. Ele pode ser construído a partir de documentos ou de relatos verbais produzidos em condições planejadas para a finalidade que o mapeamento objetiva. No presente trabalho, constrói-se o mapa cognitivo a partir de documentos já existentes, que revelam os conceitos que guiam o andamento do processo de reestruturação da empresa e seus desafios futuros.

Conforme Huff (1990), os mapas têm sido muito utilizados no estudo de estratégias, também para explorar a visão estratégica de executivos centrais, para compreender o processo de formulação de estratégias e suas mudanças com o tempo, para analisar a interpretação do ambiente e entender como as empresas identificam vantagens competitivas.

Há uma diversidade de tipos de mapas. Isso porque pode-se estabelecer várias relações possíveis entre os conceitos ou elementos cognitivos. Bastos (2000), Bougon (1983) e Huff (1990) destacam que essas relações podem ser de associação, de grau de similaridade, do valor relativo, do vínculo causal e de argumentação. Os mapas também podem levar a fazerse inferências sobre um sujeito a partir de sua fala. 
Fiol e Huff (1992), em trabalho posterior, destacam algumas alternativas de mapeamento mais usadas na pesquisa organizacional, voltadas para três diferentes aspectos dos processos cognitivos: (a) os mapas de identidade, que identificam os principais atores, eventos e processos do "terreno"; (b) os mapas de categorização, voltados para as relações entre tais entidades e focalizam as categorias que estruturam a organização do conhecimento pelo gestor. Descrevem hierarquias de conceitos e dimensões psicológicas subjacentes e, (c) mapas causais e de argumentação, centrados no raciocínio causal que liga entidades ao longo do tempo, ou no raciocínio que embasa decisões.

Os mapas causais são os mais difundidos nos estudos gerenciais, conforme Bastos(2000). Eles fornecem uma compreensão dos vínculos que os indivíduos estabelecem entre ações e resultados ao longo do tempo. Dentro dos mapas causais, ainda há várias formas de construí-los. Escolheu-se no presente trabalho, a metodologia conhecida com SODA (Strategic Options Development Analysis) por parecer constituir uma forma mais clara e simplificada do mapa causal. Neste método, conforme Éden et al. (1998), são tratados os conceitos que estruturam o mapa. Para captar de forma mais fidedigna a perspectiva da pessoa, o conceito é enunciado bipolarmente como ações, já que outros podem interferir nesta ação. A vinculação entre conceitos respeita a relação meio-fim, antecedente-conseqüente, conduzindo a um objetivo final.

A metodologia SODA trabalha com três tipos de conceitos. As metas (G), que devem vir no topo do mapa. Em seguida, vêm aqueles que expressam direções estratégicas (D.E.) e que revelam consequiências de longo prazo, elevado custo, irreversibilidade e que podem requerer uma mudança em cultura para acontecerem. Logo abaixo, coloca-se as opções potenciais (O.P.).

É importante salientar que, nesta metodologia, os vínculos que juntam os conceitos devem ser interpretados como 'pode conduzir $a^{\prime}$, ou 'pode implicar em'. Portanto, um conceito explicará como um outro poderia ocorrer ou poderia ser um meio possível de alcançar uma opção.

Também é válido ressaltar-se que o mapeamento cognitivo é considerado uma das técnicas "soft" de modelagem empresarial. Isso quer dizer que os modelos são vistos como ferramentas para pensar e explorar consequiências de possíveis decisões. Além disso, significa que há reduzida formalização, não uso da matemática e são impregnados de interpretações. Assim, não há um mapa correto, cada pessoa interpreta e valora ações de acordo com suas crenças e interpretações da realidade.

Para melhor compreensão do mapa cognitivo a ser apresentado, faz-se a seguir uma breve passagem pelo tema Mudança Organizacional. Em seguida, trata-se do histórico das modificações que estão ocorrendo no setor de Telecomunicações e da reestruturação interna da empresa Telemar S/A.

\section{A Mudança Organizacional}

O pensamento sobre a Mudança Organizacional conheceu importantes modificações ao longo da história. Demers (1999) apresenta o pensamento sobre a Mudança Organizacional e estratégica numa perspectiva histórica, fazendo as relações entre a transformação do meio e essas modificações importantes no pensamento sobre a mudança organizacional. Ela divide 
em três grandes períodos: Pós $2^{a}$ Guerra: crescimento e adaptação, Meados dos anos 70: Morte ou Transformação e Anos 90: Aprendizagem e Evolução.

Segundo essa autora, o período após a Segunda Guerra Mundial foi caracterizado por um alto crescimento e uma grande estabilidade econômica que se seguiu até os meados dos anos 70. Predominava um sentimento generalizado de que tudo era possível e a impressão que se tinha da mudança organizacional era que toda a mudança era sinônimo de progresso e de crescimento.

Nos meados dos anos 70, o cenário era de recessão ocasionada em grande parte pela crise do petróleo, agravado ainda pela nova crise do fim dos anos 70 e pela chegada de novos concorrentes na cena internacional no começo dos anos 80. Foi a era do econômico e do livre mercado. A idéia que se tinha da mudança organizacional, segundo Demers (1999), era de um evento dramático, uma crise na vida da organização, algo custoso e difícil de realizar. A transformação visava reposicionar a organização num meio que mudava de maneira imprevisível e repentina.

Já nos anos 90, há um sentimento generalizado de que a única coisa certa, previsível, é a mudança. Na perspectiva atual, conforme Motta (1999), não somente na organização, mas em geral, a mudança vem aparecendo como inevitável e também como necessária à sobrevivência. A mudança é hoje vista como algo inerente ao funcionamento das relações mundiais, inclusive, da organização. Como afirma Motta:

"Os fatos se alteram com rapidez, e o mesmo acontece com as idéias. Encurta-se o tempo para planejar, experimentar e agir. As mudanças terão que ser perseguidas e introduzidas antes de se saber seu total sentido e sem garantia de êxito. A intensidade da presente revolução, tecnológica e administrativa, já não deixa alternativas senão a de segui-la com a própria rapidez que a caracteriza"(1999;xiii).

Voltando-se mais para a organização, Demers (1999), numa perspectiva mais atual da mudança organizacional, revela que ela não é mais vista como um evento raro e subversivo, mas uma realidade cotidiana. A mudança é um negócio que envolve todos os membros da organização. O dirigente se torna um agente de mudança, entre outros, que certamente tem mais poder que os outros e este poder serve para facilitar a mudança, mais do que controlar. Não há uma preocupação somente com a estratégia e a estrutura de maneira formal e tangível, mas põem a atenção sobre as dimensões cognitivas e culturais, incitando os gestores a se interessarem pela gestão dos sentidos.

Adota-se neste trabalho uma perspectiva simbólico-interpretativa, isto é, a visão de que o mundo real é construído a partir de nossas experiências, idéias e afirmações. Assim, cada organização interpreta seu ambiente conforme as percepções de seus indivíduos. A mudança é, então, única e constitui-se de uma experiência concreta que se passa num meio organizacional, cuja história e prática possuem alguma diversidade.

De fato, o sucesso de uma transformação radical necessitaria não somente de uma gestão racional, mas igualmente simbólica, fazendo chamar as emoções. Nesse sentido, é válido analisar os discursos dos dirigentes, para verificar os conceitos que os levam a conduzir, ou melhor, facilitar a mudança. O discurso utilizado pelos dirigentes influencia as percepções das pessoas em relação à mudança e são captados de formas distintas por cada indivíduo na organização. 


\section{O processo de mudança no Setor de Telecomunicações e a Telemar S/A}

As pressões das grandes corporações transnacionais, a descoberta de novas tecnologias, a situação na qual se encontram os Estados Nacionais, instituições e sociedade, o aparecimento de novas formas de concorrência e as modificações nas regras políticas ou sociais são algumas características do mundo atual. As telecomunicações constituem os instrumentais que permeiam esse processo com seus equipamentos, cada vez mais aprimorados e disseminados pelo mundo.

As novas tecnologias de informação e de comunicações vêm nos poupando tempo e "encurtando distâncias" e a tendência observada no mundo para o setor de telecomunicações é de um avanço tecnológico ainda mais acelerado. Na onda da mundialização, reduz-se o tempo de transporte de dados, ligando-se espaços distantes e encorajando-se o internacional, a orientação global. O setor vive hoje um processo de efervescência tecnológica convivendo com profundas modificações na sua gestão.

O Setor de Telecomunicações no Brasil foi desde cedo tomado pelo Estado como um serviço de utilidade pública, já que era considerado estratégico para o desenvolvimento do país. Na última década, o governo vem realizando uma reforma que tem por objetivo tornar mais ágil a administração pública, tornando seus serviços mais acessíveis e de melhor qualidade, além da intenção de reduzir drasticamente o déficit público. Nesse sentido, vem repensando suas formas de atuação e deixando de agir como gestor para atuar mais como regulador das atividades.

Nesse contexto, mudar é inevitável e também necessário à sobrevivência das organizações. Com a privatização do setor, muita coisa vem sendo modificada. As empresas de telecomunicações, antes estatais, sofreram todo um processo de reestruturação interna para tornarem-se privadas e enfrentar a concorrência, antes inexistente por se tratar de um setor onde havia monopólio estatal.

A Telemar S/A, assim como as outras empresas do setor, vêm passando por uma significativa reorientação de missão, objetivos, diretrizes e políticas para se adaptar a essa nova situação. A mudança no setor já ocorreu e as empresas nascentes devem estar adaptando-se o mais breve possível nesse novo ambiente para sobreviver da melhor forma possível.

Assim, o discurso nessas organizações privatizadas tem sido um só: tornar a empresa competitiva no mercado, enfocando a satisfação do cliente, pois este é quem mais contribui com sua fidelidade no serviço prestado, para o aumento da receita da organização e, conseqüentemente, para a sua permanência no mercado.

A seguir, apresentamos o mapa cognitivo proposto para interpretação dos discursos do presidente da companhia em questão.

\section{Mapa Cognitivo proposto}

Apresentamos a seguir o mapa cognitivo sobre três discursos do presidente da Telemar, Manoel Horácio, a respeito das modificações que ocorreram na empresa após o 
processo de privatização e sobre os desafios no ano 2000. As informações foram obtidas em entrevistas documentadas que foram concedidas por este presidente ao jornal impresso da empresa entre 1999 e 2000. Em anexo, estão as entrevistas concedidas pelo presidente marcadas conforme as diretrizes da metodologia SODA $^{\text {iii }}$ para deixarem claras as fontes de elaboração do mapa cognitivo abaixo.

Figura 1- Mapa Cognitivo proposto

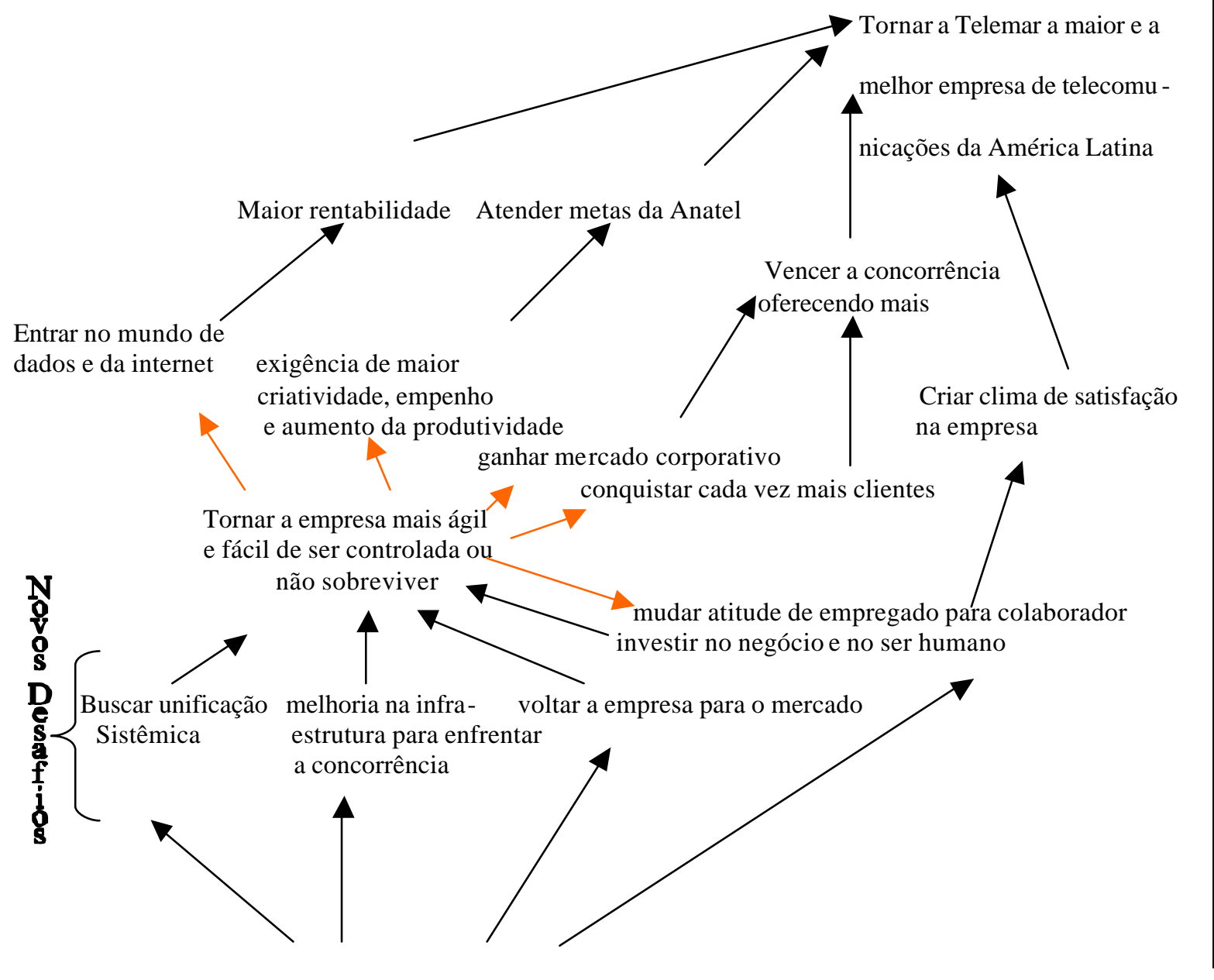




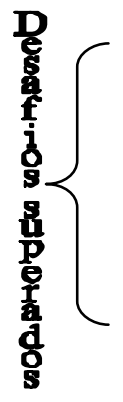

\section{Uma interpretação do mapa}

Como já foi ressaltado anteriormente, o mapa cognitivo é uma ferramenta útil para uma melhor compreensão dos fenômenos organizacionais. Assim, ele pode facilitar o estudo e a compreensão da mudança ocorrida na Telemar S/A com a privatização. No entanto, não há uma só interpretação para o mapa, assim como, pessoas diferentes constróem mapas distintos acerca dos mesmos discursos. O que se propõe aqui, então, é apresentar uma interpretação do mapa cognitivo.

Os mapas cognitivos, sendo representações, schemas ou modelos mentais construídos pelos indivíduos, a partir das suas interações e aprendizagens em um domínio específico do seu ambiente, têm a função de dar sentido à realidade e permitir lidar com os problemas e desafios que esta lhes coloca. Assim, o presidente da Telemar S/A, Manoel Horácio, tenta, no seu discurso, reforçar a idéia compartilhada hoje a respeito da mudança: a de que ela é uma realidade cotidiana que envolve todos os membros da organização. Dentro de um contexto tumultuado de reformas estruturais e tecnológicas, põe acento na importância de uma empresa mais ágil e mais fácil de ser controlada (16 empresas agora são uma só, conforme slogan divulgado). Caso contrário, não há a mínima condição de sobreviver num ambiente competitivo, como o agora instaurado. Esta mesma unificação sistêmica, a melhoria na infraestrutura para enfrentar a concorrência, a direção da empresa para o mercado e o investimento no negócio e no ser humano ficam como opções potenciais para tornarem a Telemar S/A mais ágil e de fácil controle.

As Direções Estratégicas, que vêm logo acima do conceito básico -Tornar a empresa mais ágil e fácil de ser controlada - , são aqueles conceitos que normalmente se relacionam a uma ou mais das metas, apoiando-as, e que podem consistir em implicações de longo termo, alto custo, irreversíveis e que precisam de um conjunto de ações para fazer acontecer ou podem requerer uma mudança em cultura. No discurso do referido presidente, pode-se inferir as seguintes Direções Estratégicas: 1)entrar no mundo de dados e da internet; 2)exigir maior criatividade, empenho e aumento da produtividade; 3)ganhar mercado corporativo; 4)conquistar mais clientes e; 5) mudar atitude de empregado para colaborador.

Interligadas e apoiadas nas Direções Estratégicas estão as Metas, que são os conceitos estruturadores de ordem superior. As Metas identificadas nos discursos foram as seguintes: 1)maior rentabilidade; 2)atender metas da Anatel - agência reguladora do setor; 3)vencer a concorrência oferecendo mais; e 4)criar clima de satisfação na empresa. Além dessas Metas, foi identificada uma meta ainda maior: a Telemar S/A pretende ser a maior e a melhor empresa de telecomunicações da América Latina. 


\section{Considerações Finais}

O Mito do Serviço Público, muito difundido no Brasil, de que ele é excessivamente burocratizado, ineficiente e inchado, ao contrário das organizações privadas - essas consideradas ágeis, flexíveis e facilmente adaptáveis às novas demandas -, não deve ser utilizado como explicação para as novas reorientações das empresas hoje privatizadas. Isso porque essas generalizações não condizem com a realidade de certas organizações existentes, como era o caso da antiga Telebahia S/A (prestadora de serviços de telecomunicações na Bahia- estatal), classificada entre as melhores empresas estatais em 1998, ocupando destaque entre o sistema Telebrás.

As lógicas das organizações públicas e privadas são evidentemente distintas, mas isso não quer dizer que haja uma hierarquia entre ambas. $\mathrm{O}$ que se deve prestar atenção são às mudanças que estão ocorrendo no ambiente setorial e no mundo contemporâneo. As modificações chegam e são inevitáveis à sobrevivência. Os que não acompanham as mudanças, não se adaptando a elas, acabam por definhar, já que agora, o setor está aberto à concorrência.

Para tanto, o discurso do presidente da Telemar S/A, Manoel Horácio Francisco da Silva, vem confirmar o discurso atual do foco no cliente, na melhoria contínua dos recursos humanos- estes fatores-chave da empresa -, em tornar a empresa mais ágil e mais rentável. Suas metas são ambiciosas e os obstáculos são imensos, mas seu discurso revela-se bastante positivo de forma a estimular seus colaboradores a adaptar da melhor forma possível a empresa ao novo ambiente que se desenha.

O seu discurso mostra-se bastante preocupado com o mercado, a concorrência e os clientes. Além disso, prega a valorização do capital humano, e, em troca, exige cada vez mais comprometimento dos colaboradores com os clientes, com a rentabilidade do negócio, criatividade, empenho e aumento de produtividade dos colaboradores.

É um discurso típico do mundo atual e que vem conduzindo a modificações nas empresas: cobra-se mais dos funcionários, oferece-se mais aos clientes, visando o crescimento da empresa.

\section{Bibliografia}

BASTOS, A.V.B. Organização e Cognição: o que emerge desta interface? 2000.

BASTOS, A. V.B. Mapas cognitivos: ferramentas de pesquisa e intervenção em processos organizacionais. 2000.

CSÁNYI, V. (1995). The biological bases of cognitive maps. Em: E. Lazlo et al. (eds). The evolution of cognitive maps- new paradigms for the twenty-first century. Amsterdam: Gordon and Breach.

DEMERS, Christiane. De la Gestion du Changement à la Capacité de Changer. L'Evolution de la Recherche sur le Changement Organisationel. Depuis 1945 jusqu'à aujourd'hui. Gestion, vol.24, n³, automne 1999 
EDEN, C. e Ackerman, F, (1998). Analysing and comparing idiographic causual maps. Em: C. Eden e J.C. Spencer (eds.) Managerial and Organizational Cognitions- Theory, methods and research. London: Sage, pp. 192-209.

FIOL, C. M. e HUFF, A. (1992). Maps for managers: where are we? Where we go from here? Journal or Management Studies, 29 (3): 267-85

GARDNER, The mind's new science: a history of the cognitive revolution. New York: Basic Books. 1985.

HUFF, A. S. (1990). Mapping Strategic Thought. Em A. S. Huff (Ed). Mapping Strategic Thought. Chichester: Wiley, p.11-49.

JR, Henry P. e Lorenzim Peter. The New Leadership Paradigm: Learning and Cognition in Organizational. Sage Publications, 1992

LASZLO, E.; Masulli, I.; Artigiani, R. e Csányi, V. (1995). The evolution of cognitive maps - new paradigms for the twenty-first century. Amsterdam: Gordon and Breach Publishers.

NICOLINI, Davide. Comparing Methods for Mapping Organizational Cognition. Organization Studies, 1999, 20/5.

TENBRUNSEL, A.E.; Galvin, T. L.; Neale, M.A. e Bazerman, M.H. (1996). Cognitions in Organizations. Em, S. Clegg, C. Hardy e W. Nord, Handbook of Organization Studies. London: SAGE, p.148-174.

PIDD, M. Modelagem Empresarial: Ferramentas para a Tomada de Decisão. Porto Alegre, 1998. Bookman.

SWAN, J. (1997). Using cognitive mapping in management research: decisions about technical innovation. British Journal of Management, vol. 8, 183-198.

WALSH, James P. Managerial and Organizational Cognition: Notes from a trip down memory lane. Organization Science 6/3: 280-334. 1995.

WEICK, K. E. Enactment Process on Organizations. In: B, Staw and G. Salancik (eds.). New Directions in Organizational Behavior. Chicago: St. Clair Press, 1977.

\section{Anexos}

Anexo 1- Declaração do presidente da Telemar, Manoel Horácio, no Jornal Telemar Corporativo- Ano 1- Dezembro - no 8- 1999.

O primeiro ano da Telemar foi difícil, mas conseguimos passar pelas crises com bastante desenvoltura/ e, melhor do que os nossos concorrentes. A primeira grande prova foi a 
mudança de marca, / que refletiu a transformação de 16 empresas em uma só. Depois veio o plano de numeração, / que alterou completamente o sistema nacional das ligações a longa distância, exigindo da companhia um esforço enorme./ Novamente passamos com louvor: fomos a primeira empresa a ser liberada pela Anatel. / O incêndio da Central Alvorada, no Rio, em agosto, foi a terceira grande prova. / Além do plano de assistência ao consumidor, batemos o recorde mundial em reconstrução: em 15 dias,/ a estação queimada estava em pleno funcionamento.

Estamos vivendo, agora, a quarta etapa de trabalho/ e contamos com a garra de todos os Colaboradores para alcançar as metas da Anatel, que neste último mês G/ estão sendo cumpridas em quase sua totalidade. Foi um esforço brutal e estou confiante/ que chegaremos ao final de 99 com quase todos os objetivos atingidos.

O desafio futuro será continuar a conquistar o cliente, ganhar o mercado corporativo e entrar D.E./ de maneira competitiva no mundo de dados e da Internet. Neste mercado, exercitaremos nossa habilidade em tornar D.E./ a Telemar mais rentável ainda G. Em março teremos nosso backbone e, com uma/ rede de multi-serviços, estaremos ainda mais preparados para enfrentar a competição./ No ano 2000, a partir de janeiro, quando começa a operar a empresa espelho da Telemar, a grande batalha/ será vencer a concorrência, oferecendo mais e mais ao cliente. Nossas armas estão aqui dentro: são os colaboradores./ Vamos investir no negócio sim, mas vamos investir no ser humano, treinando-o OP./ e motivando-o a continuar a luta, sempre voltado para o futuro. E isso é apenas o começo.../

Legenda:

I - começo e final das frases de 10 a 12 palavras;

G - Metas identificadas;

D.E.- Direções Estratégicas;

O.P.- Opções Potenciais.

Lista de conceitos:

- conseguimos passar melhor pelas crises do que os concorrentes;

- provas da superação: mudança de marca, 16 empresas em uma só, plano de numeração, primeira empresa a ser liberada pela Anatel, reconstrução da Central Alvorada em 15 dias após o incêndio;

- Conta-se com os colaboradores para alcançar as metas da Anatel. Este mês elas foram quase totalmente cumpridas;

- confiança que chegaremos ao final de 99 com quase todos os objetivos atingidos ;

- Desafios de conquistar clientes, ganhar mercado corporativo e entrar no mercado de dados e da internet;

- Maior rentabilidade;

- Infra-estrutura (backbone) para estar mais preparados para enfrentar a competição ;

- Vencer a concorrência, oferecendo mais e mais ao cliente;

- Investir no negócio e no ser humano.

Anexo 2- Presidente aplaude colaboradores e fala dos desafios para o ano 2000. Jornal Corporativo Telemar. Ano II- Janeiro- $\mathrm{n}^{\circ} 9-2000$. 
O primeiro desafio foi transformar as 16 empresas em uma só e adotar uma só marca./ A campanha de lançamento da marca Telemar foi o case publicitário de maior sucesso / do país envolvendo mudança de nome de empresas.

O segundo grande desafio foi a negociação com fornecedores e elaboração de novos contratos,/ próximo a um terceiro desafio, que exigiu um esforço enorme de todos os colaboradores:/ a mudança do plano de numeração para as ligações à longa distância. De acordo com o presidente,/ foi neste momento que a Telemar mostrou para o mercado que, mesmo sem operador internacional,/ a companhia é eficiente, competente, e isso só foi possível porque ela é formada por profissionais/ capacitados que conhecem o negócio.

Nossa capacidade foi ratificada: a Telemar é a única empresa, entre as quatro operadoras,/ que tem um atestado de qualidade. Somo a única que recebeu da Anatel uma carta/ atestando que realizamos corretamente o trabalho de mudança do plano de numeração.

Paralelo a tudo isso, a Companhia trabalhava a todo vapor para atender as metas da Anatel G,/ o quarto desafio. Vocês, da Regional Bahia, a exemplo de outras empresas do grupo, alcançaram todos/ os itens e sei que isso só foi possível graças ao empenho excepcional dos colaboradores./ Eu sempre acreditei que chegaríamos lá, que atingiríamos nossas metas e nós atingimos. Vocês merecem aplausos.

O próximo desafio é ganhar o cliente encarando de frente a concorrência D.E. Entre/ os planos da Telemar está o de ganhar o mercado corporativo e entrar/ no mundo da Internet D.E. Para isso a empresa terá que, neste ano,/ buscar uma eficiência econômica maior e concluir a unificação sistêmica./ Todos esses desafios fazem parte de um projeto maior que é tornar a Telemar,/ hoje a maior empresa de telecomunicação da América do Sul, na maior e melhor da América Latina G.

Legenda:

I - começo e final das frases de 10 a 12 palavras;

G - Metas identificadas;

D.E.- Direções Estratégicas;

O.P.- Opções Potenciais.

Lista de conceitos:

- O primeiro desafio foi transformar as 16 empresas em uma só e adotar uma só marca;

- O lançamento da marca Telemar foi o case publicitário de maior sucesso do país envolvendo mudança de nome de empresas.

- O segundo grande desafio foi a negociação com fornecedores e elaboração de novos contratos;

- O terceiro desafio foi a mudança do plano de numeração para as ligações à longa distância; isso mostrou para o mercado que a companhia é eficiente, competente, formada por profissionais capacitados que conhecem o negócio.

- O quarto desafio: a Telemar foi a única empresa que tem um atestado de qualidade da Anatel;

- Trabalho para atender as metas da Anatel;

- Regional Bahia alcançaram todos os desafios graças ao empenho excepcional dos colaboradores; 
- Próximo desafio: ganhar o cliente encarando de frente a concorrência

- Planos da Telemar: ganhar o mercado corporativo e entrar no mundo da Internet;

- A empresa terá que, neste ano, buscar uma eficiência econômica maior e concluir a unificação sistêmica;

- Tornar a Telemar, hoje a maior empresa de telecomunicação da América do Sul, a maior e melhor da América Latina.

Anexo 3- O maior capital de uma empresa é o humano. Jornal Corporativo Telemar- Ano 1Maio- nº 1999

Uma só empresa: Temos que ter apenas uma liderança, diretrizes básicas e políticas iguais, com enfoques regionais/ para atacar as diferenças de mercado. A empresa tem que ser uma só, mais ágil, fácil de ser controlada C.B../ e voltada para o mercado OP. Para isso criamos uma marca única, uma estrutura formada por cinco regionais:/ Rio de Janeiro (filial RJ), Minas Gerais (filiais MG e ES), Bahia (filiais BA, SE, AL), Pernambuco (filiais PE, PB, RN) e Ceará (filiais CE, PI, MA, PA, AP, AM, RO).

Cliente rei: Dentro de uma cultura de monopólio ainda chamamos o cliente de usuário. $\mathrm{Na}$ realidade ele não é usuário/, mas paciente. Um consumidor que pacientemente espera ser sorteado com um telefone,/ paga um preço alto e reclama por melhores serviços./ Se não olhamos o cliente como sua majestade, perderemos a guerra D.E../ porque estamos saindo de um ambiente de monopólio para um ambiente competitivo.

Rede própria: Nesse ambiente competitivo temos a possibilidade de trabalhar com produtos aos quais/ antes não tínhamos acesso, como por exemplo, o longa distância. / Dentro de cinco meses teremos nossa rede ótica própria de longa distância,/ nosso backbone, nos 16 estados.

Capital Humano: A transformação da empresa ocorrerá se mudarmos nossa atitude de empregado para colaborador D.E.// todos responsáveis pela satisfação do cliente, qualidade e rentabilidade do negócio./ $\mathrm{O}$ ambiente competitivo exigirá mais criatividade, maior empenho individual e conseqüente D.E./ aumento de produtividade. Teremos programas de treinamento para melhorar a eficácia e/ criar um clima de satisfação dento da empresa, que é uma das metas/ estratégicas da minha gestão. Acredito que o maior capital de uma empresa é o humano O.P.

Orçamento e Metas: Temos como objetivo o cumprimento das metas da Anatel $\mathbf{G}$ e até 30 de junho/ os acionistas aprovarão o orçamento que define a estratégia para cada filial,/ que passará a ter seu desempenho cobrado.

Concorrência: Após o ano 2001, o mercado ficará livre para os concorrentes. Na área da longa distância/ somos nós, a Embratel, a Bonari e a Canbrá. Precisamos criar novos produtos e estamos/ pensando em entrar na área da Internet, que é o futuro.

Legenda:

I - começo e final das frases de 10 a 12 palavras;

G - Metas identificadas;

D.E.- Direções Estratégicas;

O.P.- Opções Potenciais.

C.B.- Conceito Básico 
Lista de conceitos:

- A empresa tem que ser uma só, ágil, fácil de ser controlada e voltada para o mercado ;

- Deve haver enfoques regionais;

- Olhar o cliente como majestade ou perder a guerra, pois estamos saindo de um ambiente de monopólio para um ambiente competitivo;

- Possibilidade de trabalhar com novos produtos;

- Transformação da empresa ocorrerá se mudarmos nossa atitude de empregado para colaborador;

- Todos os colaboradores devem ser responsáveis pela satisfação do cliente, qualidade e rentabilidade do negócio;

- Exigência de maior emprenho individual e aumento de produtividade ;

- Cumprir metas da Anatel;

- Criar novos produtos e entrar na área da Internet .

\footnotetext{
${ }^{i}$ Entre eles, Huff (1990); Fiol e Huff (1992) e Walsh (1995)

${ }^{\text {ii }}$ Segundo a Teoria dos Construtos Pessoais, nós não temos uma maneira de fazer distinções entre nossas experiências e nossas interpretações delas e, para entender o que alguém está pensando precisamos entender suas interpretações do mundo. O nosso contato com o mundo é feito através de uma série de filtros baseados em nossa experiência prévia (Pidd, 1998).

iii As diretrizes da metodologia SODA para construção de mapas, encontram-se no texto de Éden e Ackerman (1998)
} 